Research Article

\title{
Characterization of Brazilian accessions of wild Arachis species of section Arachis (Fabaceae) using heterochromatin detection and fluorescence in situ hybridization (FISH)
}

\author{
Adriana Regina Custódio ${ }^{1,2}$, Guillermo Seijo ${ }^{3}$ and José Francisco Montenegro Valls ${ }^{2}$ \\ ${ }^{1}$ Programa de Pós-Graduação em Recursos Genéticos Vegetais, Centro de Ciências Agrárias, \\ Universidade Federal de Santa Catarina, Florianópolis, SC, Brazil. \\ ${ }^{2}$ Embrapa Genetic Resources and Biotechnology, Brasília, DF, Brazil. \\ ${ }^{3}$ Instituto de Botánica del Nordeste, Corrientes, Argentina.
}

\begin{abstract}
The cytogenetic characterization of Arachis species is useful for assessing the genomes present in this genus, for establishing the relationship among their representatives and for understanding the variability in the available germplasm. In this study, we used fluorescence in situ hybridization (FISH) to examine the distribution patterns of heterochromatin and rDNA genes in 12 Brazilian accessions of five species of the taxonomic section Arachis. The heterochromatic pattern varied considerably among the species: complements with centromeric bands in all of the chromosomes $(A$. hoehnel) and complements completely devoid of heterochromatin $(A$. gregoryi, $A$. magna) were observed. The number of $45 \mathrm{~S}$ rDNA loci ranged from two ( $A$. gregoryi) to eight ( $A$. glandulifera), while the number of $5 S$ rDNA loci was more conserved and varied from two (in most species) to four ( $A$. hoehnei). In some species one pair of 5S rDNA loci was observed adjacent to 45S rDNA loci. The chromosomal markers revealed polymorphism in the three species with more than one accession ( $A$. gregoryi, $A$. magna and $A$. valida) that were tested. The previous genome assignment for each of the species studied was confirmed, except for $A$. hoehnei. The intraspecific variability observed here suggests that an exhaustive cytogenetic and taxonomic analysis is still needed for some Arachis species.
\end{abstract}

Keywords: Crop wild relatives, groundnut, rDNA loci, Brazil.

Received: October 12, 2012; Accepted: April 18, 2013.

\section{Introduction}

Arachis L. is a South American legume genus found in Argentina, Bolivia, Brazil, Paraguay and Uruguay. This genus consists of 80 species arranged in nine taxonomic sections (Krapovickas and Gregory, 1994; Lavia et al., 2009; Valls and Simpson, 2005). Section Arachis is the most numerous (33 species) and important since it contains the cultivated peanut, $A$. hypogaea $\mathrm{L}$., and its closest wild relatives (Moretzsohn et al., 2013). In recent years, there has been renewed interest in the study and characterization of wild species of the section Arachis, particularly since prebreeding programs have shown that agronomic traits from wild species can be introgressed into the cultivated peanut (Simpson and Starr, 2001; Fávero et al., 2006) and used for peanut genetic improvement.

Cytogenetically, two basic chromosome numbers and two levels of ploidy $(2 n=2 x=18,2 n=2 x=20$ and $2 n=4 x$

Send correspondence to Adriana Regina Custódio. Embrapa Genetic Resources and Biotechnology, Caixa Postal 02372, 70770-917 Brasília, DF, Brazil. E-mail: custodiosjs@yahoo.com.br.
$=40$ ) have been reported for species included in the section Arachis (Fernández and Krapovickas, 1994; Lavia, 1996, 1998, 2000; Lavia et al., 2008; Peñaloza and Valls, 2005). Based on the distribution patterns of heterochromatic bands and rDNA loci, together with the morphological characteristics and cross-compatibility relationships, the species with $2 \mathrm{n}=20$ were arranged in five genomes: A (Robledo et al., 2009), D (Stalker, 1991; Robledo and Seijo, 2008), B, F and K (Robledo and Seijo, 2010).

Brazil has the greatest diversity of Arachis species, with representatives of the nine taxonomic sections. Diploid species of the A, B and D genomes and many local races of the cultivated peanut belonging to the section Arachis have been collected throughout the country. Species with the B and D genomes are particularly interesting because their evolutionary relationships are poorly understood and their affinities with the peanut B genome are still unclear. Five wild species of section Arachis initially considered to have the B or D genomes (A. glandulifera Stalker, A. gregoryi C.E. Simpson, Krapov. \& Valls, A. hoehnei Krapov. \& W.C. Greg., A. magna Krapov., W.C. Greg. \& 
C.E. Simpson, and A. valida Krapov. \& W.C. Greg.) grow in Brazil. The distribution range of A. glandulifera, A. gregoryi and $A$. magna extends along the southwest of Mato Grosso State in Brazil and the northeast of Bolivia. Arachis hoehnei, the genomic allocation of which is still unclear, and A. valida are currently found in western Mato Grosso do Sul State in Brazil. The populations of these species are usually small and isolated from other conspecific populations. Although these species were initially well circumscribed (Krapovickas and Gregory, 1994; Valls and Simpson, 2005), new collections have revealed interpopulational morphological variability that has blurred the interspecies boundaries.

The accessions of $A$. glandulifera (D genome) analyzed so far grow in Bolivia (Stalker, 1991; Fernández and Krapovickas, 1994; Robledo and Seijo, 2008). Although few accessions have been studied, cytogenetic analyses have revealed interpopulational variability in the karyotype formula. The only accession of $A$. gregoryi (V 14753) analyzed by fluorescence in situ hybridization (FISH) had a heterochromatin pattern similar to that of species possessing the B genome (Robledo and Seijo, 2010). Arachis hoehnei includes accessions that are morphologically similar to the type specimen. However, the few cytogenetic studies that have examined this taxon have shown that some populations need to be segregated into new species because of differences in their chromosomal complement. For example, an accession collected in Paraguay and initially considered to belong to A. hoehnei (based on morphological evidence) has been assigned to a new species, $A$. schininii Krapov., Valls \& C.E. Simpson (Valls and Simpson, 2005), since its chromosomal complement corre- sponds to that of A genome species (Peñaloza and Valls, 2005; Robledo et al., 2009).

FISH is a useful tool for characterizing Arachis species and for providing information on the karyotype and genome evolution in this genus. The use of 5S rDNA and $45 \mathrm{~S}$ rDNA as probes has revealed polymorphic patterns that have allowed the delimitation of genomes and geographic groups within the section Arachis (Seijo et al., 2004; Robledo and Seijo, 2008, 2010; Robledo et al., 2009), and genome in situ hybridization (GISH) has allowed the delimitation of genomes and the study of polyploids in this genus (Seijo et al., 2007).

In this work, we used FISH to examine the patterns of heterochromatin and 5S and 45S rDNA in Brazilian species of the section Arachis with B or D genomes in an effort to clarify their genome composition and to provide karyological information that could be helpful in delimiting the species involved. The findings of this study should improve our understanding of the wild genetic resources available under ex situ conservation in Brazil for the genetic improvement of peanut.

\section{Material and Methods}

Twelve Brazilian accessions of five Arachis species maintained in the Wild Arachis Genebank at Embrapa Genetic Resources and Biotechnology in Brasília, Brazil, were analyzed (Table 1). Roots were obtained from seeds germinated under laboratory conditions. Root apices $(1.5 \mathrm{~cm})$ were pre-treated with $2 \mathrm{mM} 8$-hydroxyquinoline for $3 \mathrm{~h}$ at room temperature and then fixed in Farmer's solution (absolute ethanol:glacial acetic acid, 3:1, v/v). Fixed root apices were digested in a solution containing $2 \%$ cellu-

Table 1 - List of the 12 Brazilian accessions of Arachis sect. Arachis and their origins.

\begin{tabular}{|c|c|c|c|c|c|c|c|c|}
\hline Arachis species & $\mathrm{BRA}^{1}$ & Collectors $^{2}$ & Accession & State $^{3}$ & Municipality & Lat (S) & Long (W) & Alt (m) \\
\hline A. glandulifera Stalker & 038687 & VOfSv & 14730 & MT & Vila Bela S. Trindade & $15^{\circ} 24^{\prime}$ & $60^{\circ} 12^{\prime}$ & 220 \\
\hline \multirow{3}{*}{$\begin{array}{l}\text { A. gregoryi C.E. } \\
\text { Simpson, Krapov. \& Valls }\end{array}$} & 012696 & VSGr & 6389 & MT & Vila Bela S. Trindade & $15^{\circ} 19^{\prime}$ & $60^{\circ} 06^{\prime}$ & 210 \\
\hline & 038733 & VOfSv & 14743 & MT & Vila Bela S. Trindade & $15^{\circ} 27^{\prime}$ & $60^{\circ} 10^{\prime}$ & 210 \\
\hline & 040002 & VS & 14957 & MT & Vila Bela S. Trindade & $15^{\circ} 22^{\prime}$ & $60^{\circ} 14^{\prime}$ & 210 \\
\hline $\begin{array}{l}\text { A. hoehnei Krapov. \& W.C. } \\
\text { Greg. }\end{array}$ & 022659 & VPoBi & 9146 & MS & Corumbá & $19^{\circ} 14^{\prime}$ & $57^{\circ} 16^{\prime}$ & 100 \\
\hline \multirow{5}{*}{$\begin{array}{l}\text { A. magna Krapov., W.C. Greg. } \\
\text { \& C.E. Simpson }\end{array}$} & 033804 & VSPmSv & 13748 & MT & Porto Esperidião & $16^{\circ} 16^{\prime}$ & $59^{\circ} 24^{\prime}$ & 400 \\
\hline & 034011 & VSPmSv & 13765 & MT & Cáceres & $15^{\circ} 48^{\prime}$ & $58^{\circ} 23^{\prime}$ & 150 \\
\hline & 033839 & VOfSv & 14724 & MT & Vila Bela S. Trindade & $15^{\circ} 19^{\prime}$ & $60^{\circ} 03^{\prime}$ & 390 \\
\hline & 033847 & VOfSv & 14727 & MT & Vila Bela S. Trindade & $15^{\circ} 21^{\prime}$ & $60^{\circ} 04^{\prime}$ & 380 \\
\hline & 038750 & VOfSv & 14750 & MT & Pontes e Lacerda & $15^{\circ} 54^{\prime}$ & $59^{\circ} 31^{\prime}$ & 320 \\
\hline \multirow[t]{2}{*}{ A. valida Krapov. \& W.C. Greg. } & 022667 & VPoBi & 9153 & MS & Corumbá & $19^{\circ} 11^{\prime}$ & $57^{\circ} 29^{\prime}$ & 100 \\
\hline & 032620 & VPzRcSgSv & 13514 & MS & Corumbá & $19^{\circ} 07^{\prime}$ & $57^{\circ} 32^{\prime}$ & 90 \\
\hline
\end{tabular}

${ }^{1} \mathrm{BRA}=$ Brazilan germplasm accession code.

${ }^{2}$ Collector abbreviations: $\mathrm{Bi}=$ L.B. Bianchetti; Gr= A. Gripp; Of=F.O. Freitas; Pm = R.N. Pittman; Po = A. Pott; Pz=E.A. Pizarro; Rc= R.C. Oliveira; $\mathrm{S}=$ C.E. Simpson; $\mathrm{Sg}=$ A.K. Singh; $\mathrm{Sv}=$ G.P. Silva; $\mathrm{V}=$ J.F.M. Valls.

${ }^{3}$ Brazilian States: MS = Mato Grosso do Sul; MT = Mato Grosso. 
lase (w/v) and $2 \%$ pectinase (v/v) dissolved in $0.01 \mathrm{~mol} / \mathrm{L}$ citric acid-sodium citrate buffer ( $\mathrm{pH}$ 4.6-4.8) and squashed in a drop of $45 \%$ acetic acid. Coverslips were removed by the dry-ice method and slides with metaphases were dried at room temperature for 1-2 days. The pretreatment of slides, the chromosome and probe denaturation for FISH and the post-hybridization washing, blocking and indirect detection with fluorochrome-conjugated antibodies were done according to Moscone et al. (1996). The primary antibodies consisted of mouse anti-biotin and sheep anti-digoxigenin conjugated to fluorescein isothiocyanate (FITC) while the secondary antibodies consisted of rabbit antimouse conjugated to tetramethyl-rodamine isothiocyanate (TRITC) and FITC-conjugated rabbit anti-sheep. Chromosomal preparations were stained with $2 \mathrm{mg}$ of 4'-6-diamidino-2-phenylindole (DAPI) $/ \mathrm{mL}$. The $5 \mathrm{~S}$ rDNA and $45 \mathrm{~S}$ rDNA loci were localized using probes isolated from genomic DNA of A. hypogaea and labeled by nick translation with digoxigenin-11-dUPT or biotin-11-dUPT (Robledo and Seijo, 2008). DAPI counterstaining subsequent to FISH resulted in a $\mathrm{C}$ banding-like pattern in which major heterochromatin bands fluoresced more intensely (Seijo et al., 2004). Chromosomes were viewed and photographed with a Leica DMRX epifluorescence microscope (Leica). Red, green and blue images were captured using appropriate filters for TRICT, FITC and DAPI excitation, respectively. Digital images were combined and processed using Photoshop v.7.0 (Adobe).

\section{Results}

The 12 germplasm accessions of the five species analyzed had $2 \mathrm{n}=2 \mathrm{x}=20$ chromosomes. Representative metaphases after FISH treatment are illustrated in Figure 1 and a summary of the heterochromatic pattern and of the rDNA loci is presented in Table 2.

The karyotype of the accession of $A$. glandulifera was very asymmetric and consisted mainly of submetacentric or subtelocentric chromosomes (Figure 1A). Eight pairs of chromosomes had large blocks of heterochromatin. Most of these bands were situated near the centromeric region in subtelocentric chromosomes and in one metacentric chromosome, while a few slightly smaller bands were observed interstitially in two pairs of chromosomes (one subtelocentric and one metacentric). Eight 45S rDNA loci (four proximal, two interstitial and two distal) were distributed in four chromosome pairs of this accession. Six of the observed sites did not correspond to secondary constrictions, while the remaining two formed extended constrictions that separated large satellites from the proximal segment of the respective arms. Two large distal 5S rDNA loci were detected in the long arms of one submetacentric pair of chromosomes.

The complement of $A$. hoehnei consisted mainly of metacentric chromosomes of similar size, except for one pair that was almost half the size of the largest one (Figure
1B). All of the chromosomes had large heterochromatic bands in the centromeric region (Figure 1B). Four 45S rDNA loci were observed in the proximal segment of the long arm of two chromosomal pairs; three of these loci formed extended secondary constrictions in most of the cells analyzed. Four 5S rDNA loci were also observed. Two of them (the larger ones) were adjacent to the $45 \mathrm{~S}$ rDNA loci, the former being located distally with respect to the latter. The other two (smaller ones) were located on the remaining chromosomes that bore $45 \mathrm{~S}$ rDNA loci, but in the short arms.

The accessions of A. gregoryi had symmetric karyotypes and their chromosomes did not have centromeric heterochromatic bands (Figure 1C-E). However, when prometaphases were analyzed, differentially stained blocks were observed in the centromeric region of some chromosomes of accession V 6389 (Figure 1D). Although these blocks stained differentially this staining did not correspond to $\mathrm{DAPI}^{+}$heterochromatin such as that seen in other Arachis species. These blocks may simply correspond to early chromatin condensation in the centromeric region, as observed in some Arachis species. Two of the three accessions (Figures 1D,E) had one pair of chromosomes with proximal $45 \mathrm{~S}$ rDNA loci located at secondary constrictions. The other accession of $A$. gregoryi (Figure 1C) has an additional pair with proximal $45 \mathrm{~S}$ rDNA loci that were not associated with secondary constrictions. The two 5S rDNA loci detected were located proximally in the long arms of a metacentric chromosomal pair.

The five accessions of A. magna had chromosomal complements that consisted exclusively of metacentric chromosomes (Figure 1F,G). These complements were completely deprived of heterochromatic blocks. All of the samples had one pair of 5S rDNA loci located proximally on the long arm of a metacentric chromosomal pair. In contrast, the number of $45 \mathrm{~S}$ rDNA was variable. Two loci were detected in three accessions (V 13748, V 14727 and V 14750), four in accession $V 13765$ and six in accession $V$ 14724. In the latter accession and in V 14727, one pair of $45 \mathrm{~S}$ rDNA loci was adjacent to the $5 \mathrm{~S}$ rDNA loci.

The two accessions of $A$. valida analyzed had symmetric karyotypes (Figure 1H). There were no centromeric bands of heterochromatin but in accession V 13514 one heterochromatic band was located distally on the long arms of the chromosomal pair bearing the 5S rDNA loci. The pattern of rDNA was similar in both accessions, i.e., six $45 \mathrm{~S}$ loci and two $5 \mathrm{~S}$ rDNA loci, with one pair of $45 \mathrm{~S}$ loci located adjacent to the $5 \mathrm{~S}$ loci.

\section{Discussion}

The Brazilian accession of A. glandulifera had a similar chromosomal complement and pattern of heterochromatic bands to those found in Bolivian accessions analyzed so far (Robledo and Seijo, 2008). The number of $45 \mathrm{~S}$ rDNA sites was the highest detected among the species 

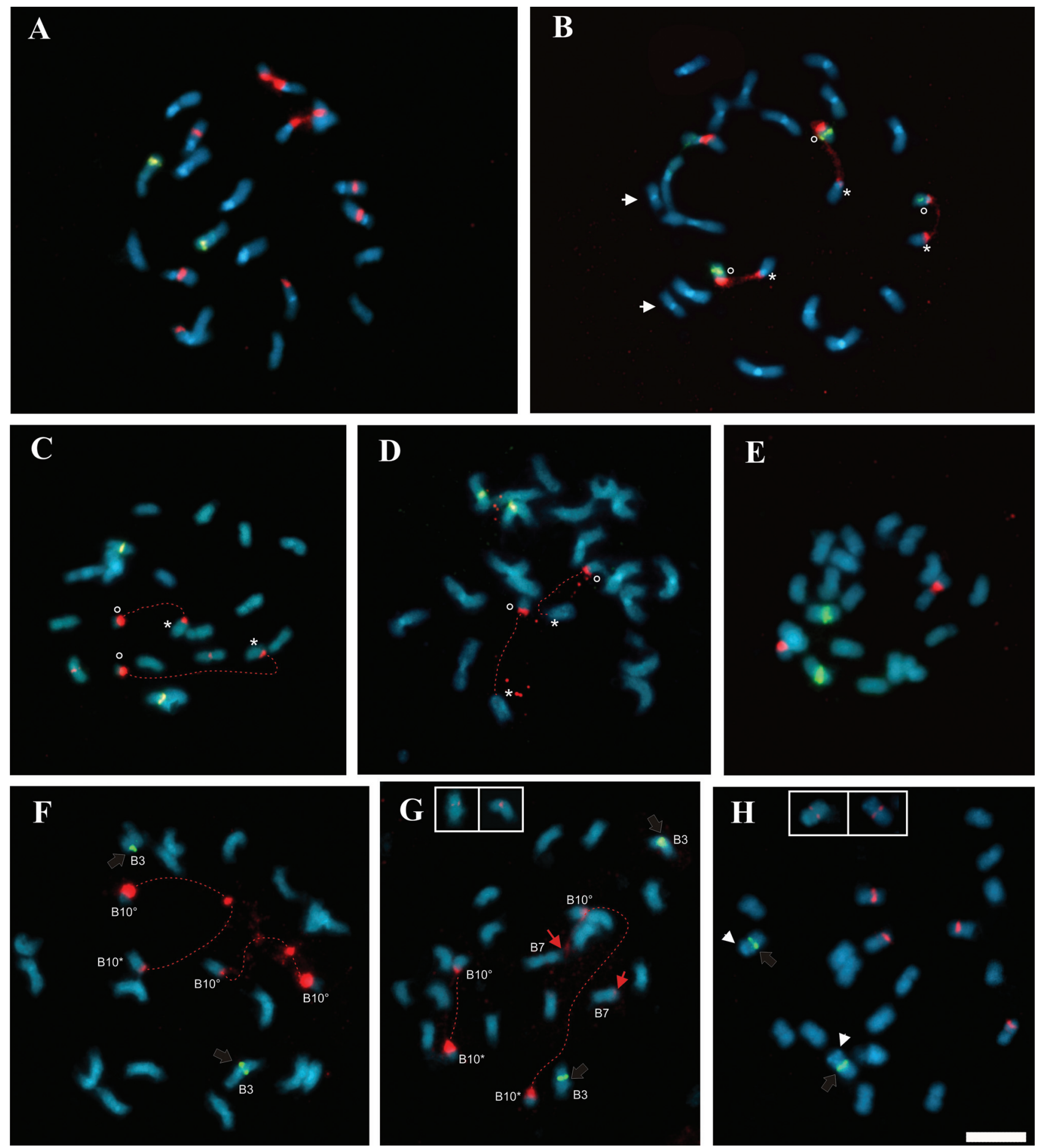

Figure 1 - Somatic metaphases of Brazilian accessions of Arachis, sect. Arachis, after heterochromatin detection and double fluorescence in situ hybridization (FISH) of the rDNA genes. (A) A. glandulifera (14730), (B) A. hoehnei (V 9146), (C) A. gregoryi (V 14743), (D) A. gregoryi (V 6389), (E) A. gregoryi (V 14957), (F) A. magna (V 13765), (G) A. magna (V 14724) and (H) A. valida (V 13514). Yellow-green fluorescein isothiocyanate (FITC) signals on the chromosomes correspond to the 5S rDNA probe and red tetramethyl-rhodamine isothiocyanate (TRITC) signals to the 45S rDNA probe. DAPI counterstaining (light blue) subsequent to FISH was used to highlight the heterochromatin bands and to stain euchromatin. The letter B followed by numbers (in $\mathrm{F}$ and $\mathrm{G}$ ) indicates possible homeologies between the $A$. magna accessions studied here with the chromosomes of A. ipaënsis. In (H), B10 refers to the corresponding chromosomal pair of previously studied accessions of $A$. valida. In the cases in which the secondary constriction is extended, the short arm and the proximal segment of the long arm are indicated by an asterisk and the separated satellite is marked by a degree sign. The satellites and their proximal segments are linked by a dashed red line. White arrows (in B) indicate the small metacentric pair of chromosomes. Red arrows (in G) indicate telomeric $45 \mathrm{~S}$ rDNA loci. Empty arrows (in F, $\mathrm{G}$ and $\mathrm{H}$ ) show the sites at which $5 \mathrm{~S}$ and $45 \mathrm{~S}$ rDNA co-localize. Inserts in $\mathrm{G}$ and $\mathrm{H}$ correspond to the chromosomes in which the $5 \mathrm{~S}$ and $45 \mathrm{~S}$ rDNA co-localize, with the hybridization of the $45 \mathrm{~S}$ loci in red. White arrowheads (in $\mathrm{H}$ ) indicate distal heterochromatic bands. Scale bar $=5 \mu \mathrm{m}$. 
Table 2 - Summary of the chromosomal markers detected in 12 Brazilian accessions of Arachis sect. Arachis. The number and position of rDNA loci and heterochromatic bands are indicated in brackets. A superscript $s$ indicates $45 \mathrm{~S}$ loci located on the same chromosome as $5 \mathrm{~S}$ loci but at different positions, while those that are co-localized at the same position are indicated with an asterisk. $\mathrm{c}$ - centromeric, $\mathrm{d}$ - distal, $\mathrm{i}$ - interstitial and $\mathrm{p}$ - proximal.

\begin{tabular}{|c|c|c|c|c|}
\hline \multirow[t]{2}{*}{ Arachis species } & \multirow[t]{2}{*}{ Accession } & \multicolumn{2}{|c|}{ Number and position of loci } & \multirow[t]{2}{*}{ Number of heterochromatic bands } \\
\hline & & 45S rDNA & 5S rDNA & \\
\hline A. glandulifera & VOfSv 14730 & $8[4 p+2 i+2 d]$ & $2(d)$ & $16[12 \mathrm{c}$ and $4 \mathrm{i}]$ \\
\hline \multirow[t]{3}{*}{ A. gregoryi } & VSGr 6389 & $2(\mathrm{p})$ & $2(\mathrm{p})$ & - \\
\hline & VOfSv 14743 & $4(p)$ & $2(\mathrm{p})$ & - \\
\hline & VS 14957 & $2(\mathrm{p})$ & $2(\mathrm{p})$ & - \\
\hline A. hoehnei & VPoBi 9146 & $4^{\mathrm{s}}(\mathrm{p})$ & $4^{\mathrm{s}}$ (i) & $20(\mathrm{c})$ \\
\hline \multirow[t]{5}{*}{ A. magna } & VSPmSv 13748 & $2(p)$ & $2(\mathrm{p})$ & - \\
\hline & VSPmSv 13765 & $4(2 *)(p)$ & $2 *(p)$ & - \\
\hline & VOfSv 14724 & $6(2 *)[4 p+2 d]$ & $2 *(p)$ & - \\
\hline & VOfSv 14727 & $2 *(\mathrm{p})$ & $2 *(p)$ & - \\
\hline & VOfSv 14750 & $2(\mathrm{p})$ & $2(p)$ & - \\
\hline \multirow[t]{2}{*}{ A. valida } & VPoBi 9153 & $6\left(2^{*}\right)[4 p+2 i]$ & $2 *(p)$ & $2(d)$ \\
\hline & VPzRcSgSv 13514 & $6\left(2^{*}\right)[4 p+2 i]$ & $2^{*}(\mathrm{p})$ & 2 (d) \\
\hline
\end{tabular}

studied here and agreed with that found for one of the three Bolivian accessions analyzed before (Robledo and Seijo, 2008). The asymmetry of the karyotype of $A$. glandulifera has been used, along with other characteristics, to propose that this species should be assigned to the D genome (Stalker, 1991). Our results confirmed that this species is peculiar, not only in its gross karyotypic structure but also in the pattern of heterochromatin and rDNA loci, as observed by Robledo and Seijo (2008). These differences have hampered the establishment of homeologies with the chromosomes of representative species and accessions of the other genomes described for the section. However, based on the limited cytogenetic data available, it appears that the D genome is more related to the $\mathrm{K}$ genome than to the other genomes (Robledo and Seijo, 2008). Studies based on molecular markers have not fully clarified the relationships of the D genome. AFLP (Tallury et al., 2005; Milla et al., 2005), SSR (Moretzsohn et al., 2004), as well as ITS and 5.8S rDNA analyses (Bechara et al., 2010) revealed that the $\mathrm{D}$ genome is closely related to $\mathrm{K}$ genome species, whereas analyses of plastid trnT-F sequences (Tallury et al., 2005) suggested a closer relationship of $A$. glandulifera with $A$. williamsii (B genome) and $A$. benensis (F genome), although with low support. Indeed, the relationships of this genome within the section are still unclear.

The pattern of centromeric bands found in accession V 9146 of $A$. hoehnei was similar to that observed in species of the $\mathrm{K}$ and A genomes studied so far (Seijo et al., 2004; Robledo et al., 2009; Robledo and Seijo, 2010). Even though the pair of small chromosomes observed in accession V 9146 was similar in size to that expected for " $A$ " chromosomes (which define the A genome), their distal chromatin did not condense allocyclically in relation to the proximal chromatin, as is characteristic of A chromosomes.
Molecular markers revealed that this accession shared greater similarity with species included in the A genome than with any other taxon (Moretzsohn et al., 2013). Classic cytogenetic analysis revealed that accession K 30006 (the type of $A$. hoehnei) did not have the A chromosome pair (Fernández and Krapovickas, 1994), although this pair is present in accession V 9923 (Peñaloza and Valls, 2005), already classified as $A$. schininii. Based on these findings and the information provided here, it appears that accessions corresponding to different biological species are currently being identified as $A$. hoehnei. This fact indicates that additional cytogenetic research is needed to clarify the taxonomic identity of currently recognized A. hoehnei accessions (except for the type accession).

Two of the three accessions of A. gregoryi showed the same distribution of rDNA loci previously reported by Robledo et al. (2010); the differences related to accession V 14743 indicate some degree of variation in this species and require additional taxonomic evaluation. However, the absence of large centromeric heterochromatic bands in the three accessions suggests that they should be classified in the B genome.

The fact that all of the Brazilian accessions of $A$. magna analyzed here lacked heterochromatic bands was consistent with their placement in the B genome and with the heterochromatin pattern previously found for this species (Robledo and Seijo, 2010). However, four of the five accessions consistently had bristles in the stipules, as in the type specimen of $A$. magna, although bristles were absent in accession V 14724. The pattern of six 45S rDNA loci and two 5S r DNA loci in accession V 14724 resembled that reported for A. ipaënsis Krapov. \& W.C. Greg. (Seijo et al., 2004). The possible homeologies between the chromosomes of this accession, currently listed under A. magna, 
with those of chromosomal pairs $\mathrm{B} 3, \mathrm{~B} 7$ and $\mathrm{B} 10$ of $A$. ipaënsis are indicated in Figure 1G. The only difference is that in accession V 14724 one pair of $45 \mathrm{~S}$ rDNA loci is adjacent to the $5 \mathrm{~S}$ rDNA loci while in $A$. ipaënsis they mapped to different arms of the same chromosome (Robledo and Seijo, 2010).

The accessions with bristles in the stipules, which were morphologically closer to the type of A. magna, showed even more divergent patterns for the 45S rDNA loci: V 13765 had four and V 13748, V 14727 and V 14750 had two each. Indeed, none of the foregoing Brazilian accessions had the eight $45 \mathrm{~S}$ rDNA loci originally described for A. magna (Robledo and Seijo, 2010) and at least one of them appeared to be more closely related to A. ipaënsis.

The findings of this study indicate that a more extensive cytogenetic and morphological analysis of a larger set of $A$. magna populations, possibly also including some of those listed under $A$. gregoryi, is needed to precisely define the B genome taxa. Such an analysis may have an impact in defining the origin of peanuts since $A$. ipaënsis (represented in genebanks by a single accession to date) has been established as the wild donor of the $\mathrm{B}$ genome of the cultigen (Grabiele et al., 2012).

The absence of heterochromatic bands in the two accessions of $A$. valida confirmed the inclusion of this species in the $\mathrm{B}$ genome, as previously proposed (Robledo and Seijo, 2010). The distally located heterochromatic band on the long arm of chromosomes bearing the 5S rDNA loci detected in accession V 13514 reinforced the similarity with the previously described features of the species (Robledo and Seijo, 2010). However, the 45S rDNA pattern differed with regard to the number and distribution of loci. The lack of one of the two $45 \mathrm{~S}$ rDNA loci previously detected in chromosome B10 and the presence of a $45 \mathrm{~S}$ rDNA locus adjacent to the $5 \mathrm{~S}$ rDNA loci are very distinctive features of the accessions analyzed here, a surprising finding since they are basically sympatric with those analyzed by Robledo and Seijo (2010). Accessions KG 30011 and 30147, both of which have been studied before, and V 9153 and V 13514 where collected in the field in 1976, 1977, 1985 and 1994, respectively, in the same area, no more than three kilometers distant from each other. Cytological data on $A$. valida include references to the presence of two pairs of satellited chromosomes in KG 30147 (Fernández and Krapovickas, 1994) and V 13514 (Peñaloza, 2000). The intraspecific structural polymorphism shown by sympatric accessions of $A$. valida certainly deserves further investigation.

\section{Conclusions}

The genome assignation of the Arachis species here analyzed was confirmed, except for $A$. hoehnei. The cytogenetic data obtained for each accession revealed intraspecific variability in most of the species, both in the number and distribution of rDNA loci. For the particular cases of A. magna and A. gregoryi, our results suggest that an exhaustive cytogenetic and taxonomic analysis of the accession identified under each name is still needed to precisely delimit the respective species.

\section{Acknowledgments}

This work is part of a $\mathrm{PhD}$ thesis by ARC who is currently supported by a post-doctoral fellowship from Coordenação de Aperfeiçoamento de Pessoal de Nível Superior (CAPES)/Conselho Nacional de Pesquisa e Desenvolvimento Tecnológico (CNPq)/Protax. JFMV is supported by a research fellowship from CNPq.

\section{References}

Bechara MD, Moretzsohn MC, Palmieri DA, Monteiro JP, Bacci Junior M, Martins Junior J, Valls JFM, Lopes CR and Gimenes MA (2010) Phylogenetic relationships in genus Arachis based on ITS and 5.8S rDNA sequences. BMC Plant Biol 10:255.

Fávero AP, Simpson CE, Valls JFM and Vello NA (2006) Study of the evolution of cultivated peanut through crossability studies among Arachis ipaënsis, A. duranensis and $A$. hypogaea. Crop Sci 46:1546-1552.

Fernández A and Krapovickas A (1994) Cromosomas y evolución en Arachis (Leguminosae). Bonplandia 8:187-220.

Grabiele M, Chalup L, Robledo R and Seijo G (2012) Genetic and geographic origin of domesticated peanut as evidenced by 5S rDNA and chloroplast DNA sequences. Plant Syst Evol 298:1151-1165.

Krapovickas A and Gregory WC (1994) Taxonomía del género Arachis (Leguminosae). Bonplandia 8:1-186.

Lavia GI (1996) Estudios cromosómicos en Arachis (Leguminosae). Bonplandia 9:111-120.

Lavia GI (1998) Karyotypes of Arachis palustris and A. praecox (section Arachis), two species with basic chromosome number $\mathrm{x}=9$. Cytologia 63:177-181.

Lavia GI (2000) Chromosome studies of wild Arachis (Leguminosae). Caryologia 53:177-181.

Lavia GI, Fernández A and Seijo JG (2008) Cytogenetic and molecular evidences on the evolutionary relationships among Arachis species. In: Sharma AK and Sharma A (eds) Plant Genome. Biodiversity and Evolution. Volume 1E. Phanerogam - Angiosperm. Science Publishers, Calcutta, pp 101134.

Lavia GI, Ortiz AM and Fernández A (2009) Karyotypic studies in wild germoplasm of Arachis (Leguminosae). Genet Res Crop Evol 56:755-764.

Milla SR, Isleib TG and Stalker HT (2005) Taxonomic relationships among Arachis sect. Arachis species as revealed by AFLP markers. Genome 48:1-11.

Moretzsohn MC, Hopkins MS, Mitchell SE, Kresovich S, Valls JFM and Ferreira ME (2004) Genetic diversity of peanut (Arachis hypogaea L.) and its wild relatives based on the analysis of hypervariable regions of the genome. BMC Plant Biol 4:11.

Moretzsohn MC, Gouvea EG, Inglis PW, Leal-Bertioli SCM, Valls JFM and Bertioli DJ (2013) A study of the relationships of cultivated peanut (Arachis hypogaea L.) and its 
most closely related wild species using intron sequences and microsatellite markers. Ann Botany 111:113-126.

Moscone EA, Matzke MA and Matzke AJM (1996) The use of combined FISH/GISH in conjunction with DAPI counterstaining to identify chromosomes containing transgene inserts in amphidiploid tobacco. Chromosoma 105:231-236.

Peñaloza APS (2000) Citogenética das espécies silvestres do gênero Arachis (Leguminosae). In: Cavalcanti TB, Walter BMT, Pereira da Silva G, Ramos AE, Ribeiro JF, Silva MC, Alves RNB and Dias TAB (eds) Tópicos Atuais em Botânica: Palestras Convidadas do $51{ }^{\circ}$ Congresso Nacional de Botânica. Embrapa Recursos Genéticos e Biotecnologia/Sociedade Botânica do Brasil, Brasília, pp 45-49.

Peñaloza APS and Valls JFM (2005) Chromosome number and satellited chromosome morphology of eleven species of Arachis (Leguminosae). Bonplandia 14:65-72.

Robledo G and Seijo G (2008) Characterization of the Arachis (Leguminosae) D genome using fluorescent in situ hybridization (FISH) chromosome markers and total genome DNA hybridization. Genet Mol Biol 31:717-724.

Robledo G, Lavia GI and Seijo G (2009) Species relations among wild Arachis species with the A genome as revealed by FISH mapping of rDNA loci and heterochromatin detection. Theor Appl Genet 118:1295-1307.

Robledo G and Seijo G (2010) Species relationships among the wild B genome of Arachis species (section Arachis) based on FISH mapping of rDNA loci and heterochromatin detec- tion: A new proposal for genome arrangement. Theor Appl Genet 121:1033-1046.

Seijo GJ, Lavia GI, Fernández A, Krapovickas A, Ducasse D and Moscone EA (2004) Physical mapping of the 5S and 18S25S rRNA genes by FISH as evidence that Arachis duranensis and $A$. ipaënsis are the wild diploid progenitors of A. hypogaea (Leguminosae). Am J Bot 91:1294-1303.

Seijo JG, Lavia GI, Fernádez A, Krapovickas A, Ducasse DA, Bertioli DJ and Moscone EA (2007) Genetic relationships between the cultivated peanut (Arachis hypogaea, Leguminosae) and its close relatives revealed by double GISH. Am J Bot 94:1963-1971.

Simpson CE and Starr JL (2001) Registration of "Coan"peanut. Crop Sci 41:918.

Stalker HT (1991) A new species in section Arachis of peanuts with a D genome. Am J Bot 78:630-637.

Tallury SP, Hilu KW, Milla SR, Friend SA, Alsaghir M, Stalker HT and Quandt D (2005) Genomic affinities in Arachis section Arachis (Fabaceae): Molecular and cytogenetic evidence. Theor Appl Genet 111:1229-1237.

Valls JFM and Simpson CE (2005) New species of Arachis (Leguminosae) from Brazil, Paraguay and Bolivia. Bonplandia 14:35-36.

Associate Editor: Marcelo Guerra

License information: This is an open-access article distributed under the terms of the Creative Commons Attribution License, which permits unrestricted use, distribution, and reproduction in any medium, provided the original work is properly cited. 